\title{
Simulation of the surface temperature anomalies in the Northern Hemisphere during the last 300 years of the Little Ice Age using a thermodynamic model
}

\author{
V. M. Mendoza ${ }^{1, *}$, B. Mendoza ${ }^{2}$, R. Garduño ${ }^{1}$, J. Adem $^{1,3}$ \\ ${ }^{1}$ Centro de Ciencias de la Atmósfera and ${ }^{2}$ Instituto de Geofísica, Universidad Nacional Autónoma de México, \\ Ciudad Universitaria, México DF, Mexico \\ ${ }^{3}$ Member of El Colegio Nacional, México DF, Mexico
}

\begin{abstract}
The last $300 \mathrm{yr}$ of the Little Ice Age are characterized by 3 minima in solar activity, known as the Maunder Minimum ( 1645-1710), the Dalton Minimum ( 1795-1823) and a minimum between $\sim 1880$ and 1930. In particular, during the Maunder and Dalton minima, surface temperature reconstructions present anomalies larger than $-0.7^{\circ} \mathrm{C}$. Experiments using an energy balance model, known as the thermodynamic climate model (TCM), show that the changes in $\mathrm{CO}_{2}$ and solar irradiance, relative to the period $1961-1990$, produced a temperature decrease of approximately $-0.27^{\circ} \mathrm{C}$ during the Maunder Minimum in the Northern Hemisphere. The incorporation of changes in low cloud cover, which we assumed as induced by the galactic cosmic rays, caused an even larger decrease in the surface temperature, which reached approximately $-0.46^{\circ} \mathrm{C}$ in the Maunder Minimum. The results of the model are compared with reconstructions of surface temperature anomalies developed by several authors, showing good agreement. We conclude that including an empirical relationship between low cloud cover and cosmic rays in the TCM produces a noticeable cooling in model results.
\end{abstract}

KEY WORDS: Maunder and Dalton minima $\cdot$ Atmospheric $\mathrm{CO}_{2} \cdot$ Solar irradiance $\cdot$ Galactic cosmic rays $\cdot$ Low clouds

Resale or republication not permitted without written consent of the publisher

\section{INTRODUCTION}

The Sun is a variable star which emits electromagnetic radiation, mass - in the form of transient and continuous (solar wind) phenomena - and energetic particles. The solar wind is a plasma that drags the solar magnetic field throughout the interplanetary space, beyond the Pluto orbit ( $40 \mathrm{au} ; 1 \mathrm{au}$ is the mean distance between the Sun and the Earth), forming a region that is known as the heliosphere. Observations of the Voyager 1 spacecraft indicate that the heliospheric termination shock is $\sim 94$ au (e.g. Webber et al. 2009). The interplanetary solar magnetic field constitutes a barrier for the galactic cosmic rays, which consist mainly of protons produced by various stellar processes in our galaxy, mainly supernova remnants (e.g. Caprioli et al. 2010). The changes in solar activity mod- ulate, among other phenomena, cosmic ray flux and the amount of solar radiation received by the planets, in particular by the Earth. There is a well-known negative correlation between cosmic rays and sunspots (e.g. Heber et al. 2006), while total solar irradiance (TSI) correlates with sunspots (e.g. Solanki \& Krivova 2006).

The ionization of the lower terrestrial atmosphere is a process produced almost exclusively by cosmic rays (Dorman 2004). Ionization contributes to the formation of ultrafine aerosols $(<20 \mathrm{~nm})$ through gas-particle processes, and to the subsequent growth of mature aerosols, which act as cloud condensation nuclei (Yu \& Turco 2000). Some authors (e.g. Svensmark \& FriisChristensen 1997, Marsh \& Svensmark 2000, PalléBagó \& Butler 2000) reported an important correlation between the variation in the low cloud cover (LCC) and the variation in the cosmic ray flux during the 
period 1983-1994, but they did not find good correlations for the case of middle and high clouds during the same period. The hypothesized cosmic ray-LCC relationship is, however, contested. While several authors maintain that cosmic rays are either the main contributor to radiative forcing through clouds (e.g. Svensmark 2007) or that they can partially affect cloud formation (e.g. Voiculescu et al. 2006), others consider that cosmic rays have a negligible effect on climate (e.g. Kristjánsson et al. 2008, Erlykin et al. 2009).

Clouds produce, simultaneously, a cooling of the Earth's surface when reflecting solar radiation and a heating by the absorption of terrestrial radiation; the net effect depends on the cloud type. High clouds, which are optically thin, tend to heat the surface by the greenhouse effect, whereas low clouds, which are optically thick, tend to cool it owing to their high albedo. In this way, a double effect of the solar activity changes on the terrestrial climate changes could be proposed: higher solar activity will produce an increase in both the solar radiation and the heating of the surface, which will be reinforced by a reduction in the LCC owing to a lower atmospheric ionization produced by a reduction in cosmic ray flux. The opposite process occurs at lower solar activity.

On entering the Earth's atmosphere, the cosmic rays interact with the atmospheric constituents, producing the so-called cosmogenic isotopes. ${ }^{10} \mathrm{Be}$ and ${ }^{14} \mathrm{C}$ are conspicuous examples of this kind of isotope (Beer et al. 2006). ${ }^{10} \mathrm{Be}$ is a useful isotope to reconstruct cosmic rays because it precipitates towards the surface about $1 \mathrm{yr}$ after its production, without presenting attenuation and phase lag effects encountered in, for instance, ${ }^{14} \mathrm{C}$. McCracken \& McDonald (2001) have found a good agreement between the available instrumental records of cosmic rays and the ice core ${ }^{10} \mathrm{Be}$ measurements from the ice core of the site Dye 3 located in Greenland (Beer 2000) along the period 1933-1976.

To test the cosmic ray-LCC relationship, we use dthe global infrared LCC annual mean anomaly (deseasoned) from the International Satellite Cloud Climatology Project (ISCCP) data base (ftp://isccp.giss. nasa.gov/pub/data/D2CLOUDTYPES/), which contains data only for the period 1984-2007. For this same period, we also used Moscow Cosmic Ray Neutron Monitor data (http://helios.izmiran.rssi.ru/cosray/main.htm). An increasing trend of $\sim 0.12 \%$ per year is apparent in the cosmic ray time profile, whereas the LCC presents a decreasing trend of $\sim 0.59 \%$ per year, i.e. it is $\sim 5$ times larger than that of cosmic ray (Fig. 1a). The origin of the LCC trend could be related to climatic or anthropogenic factors, as other authors have proposed (e.g. Usoskin et al. 2004). We fitted a quadratic curve to the raw data and detrended them. The correlation coefficients between the raw and detrended LCC data and
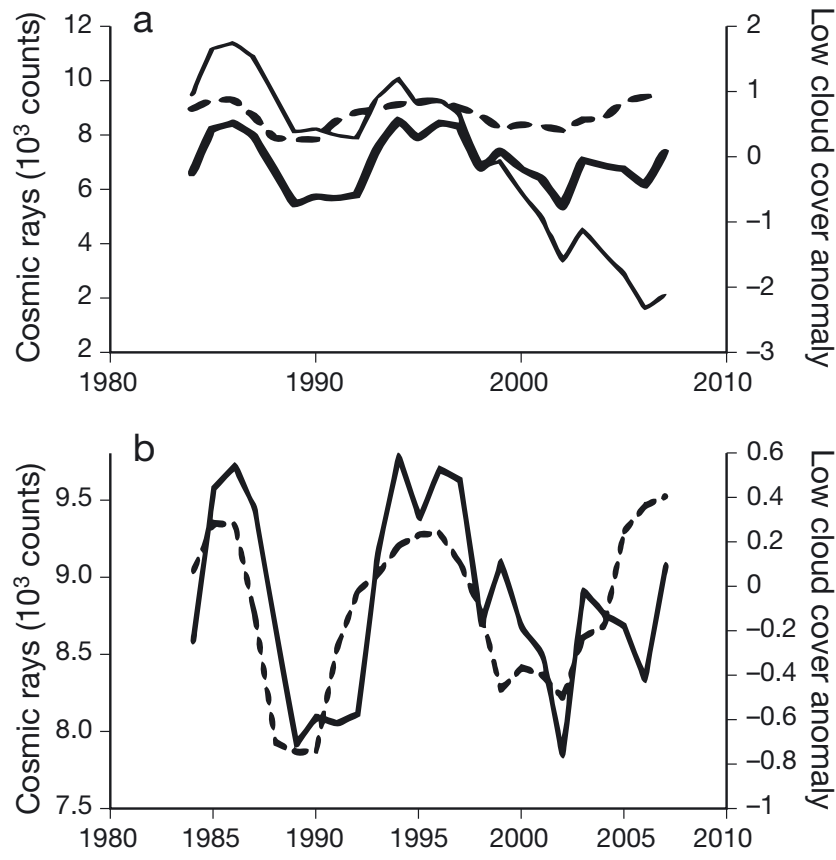

Fig. 1. Plot of the low cloud cover (LCC) and cosmic ray time series for the period 1984-2007. (a) thin line: global infrared LCC annual mean anomaly (de-seasoned) from the International Satellite Cloud Climatology Project (ISCCP) data; thick line: detrended LCC data; dashed line: Moscow Cosmic ray Neutron Monitor Data. (b) Plot of the detrended LCC (solid line) and the cosmic ray data (dashed line)

cosmic rays are 0.002 and 0.61 , respectively. From Fig. $1 \mathrm{~b}$ it is evident that the good correlation between the detrended LCC and the cosmic rays is valid for the period up to 2003. Between 2003 and 2006, there is an anticorrelation and from 2006 to 2007 there seems to be again a correlation. Therefore, we consider that the overall result is enough to assume that there is a correlation between cosmic rays and LCC.

Previous papers have modeled the effect of solar activity on the climate in the last centuries, some of them using TSI in general circulation models (e.g. Cubasch et al. 1997, Zorita et al. 2004). In a previous work, using a thermodynamic model and assuming that cosmic rays can modulate the cloud cover, Ramírez et al. (2004) showed that, during the period 1984-1990, responses in the order of a few tenths of a degree can be obtained in the Northern Hemisphere temperature using the change in $\mathrm{CO}_{2}$ and $\mathrm{LCC}$ as forcing. They did not take into account the changes in solar radiation because, during that time span, they were relatively small.

The last 300 yr of the Little Ice Age are characterized by 3 minima in the solar activity, known as the Maunder Minimum ( 1645-1710), the Dalton Minimum ( 1795-1823) and a minimum between $\sim 1880$ and 1930 that we shall refer to as the Modern Minimum. In 
particular, during the Maunder and Dalton minima, at least one surface temperature reconstruction presents anomalies $>-0.7^{\circ} \mathrm{C}$ (Briffa et al. 2001). In the present study, we extend back the work of Ramírez et al. (2004) to the period 1610-1985, including the solar radiation changes, as they were prominent during the 3 solar activity minima that occurred along the time span that we are considering.

\section{THERMODYNAMIC CLIMATE MODEL}

In the experiments reported here, we use the thermodynamic climate model (TCM), which is described in detail in previous works (Adem 1964, 1965, 1970, 1979, 1991, Adem et al. 2000). The TCM consists of an atmospheric layer of about $10 \mathrm{~km}$ thickness, which includes a single variable horizontal cloud layer, an oceanic mixed layer of $60 \mathrm{~m}$ in depth and a continental layer of negligible depth. It also includes a variable snow-ice layer over the continents and the ocean. The basic prognostic equations are those of conservation of thermal energy applied to the atmosphere-oceancontinent system, which yields 2 equations, whose variables are the mid-atmospheric temperature $\left(T_{\mathrm{m}}\right)$ and the surface temperature $\left(T_{\mathrm{s}}\right)$ of the oceans and continents. A monthly time averaging of these variables is used in the model. In order to linearize them, the absolute temperatures $\left(T_{\mathrm{m}}\right.$ and $\left.T_{\mathrm{s}}\right)$ used in the equations are taken as perturbations $\left(T^{\prime}\right)$, according to the corresponding method, from respective constant values, i.e. $T=T_{0}+T^{\prime}$, with $T^{\prime} \ll T_{0}$.

The numerical integration of the model equations is carried out using an implicit scheme, which is described in Adem et al. (2000). In this way, $T_{\mathrm{m}}$ is computed by solving the following linear elliptic differential equation:

$$
K \nabla^{2} T_{\mathrm{m}}^{\prime}+F_{1}^{\prime \prime} \frac{\partial T_{\mathrm{m}}^{\prime}}{\partial x}+F_{1}^{\prime \prime \prime} \frac{\partial T_{\mathrm{m}}^{\prime}}{\partial y}+F_{1}^{\prime} T_{\mathrm{m}}^{\prime}=F_{2}^{\prime}
$$

where $\nabla^{2}$ is the 2-dimensional Laplace operator in the map coordinates $x$ and $y, F_{1}^{\prime}, F_{1}^{\prime \prime}, F_{1}^{\prime \prime \prime}$ and $F_{2}^{\prime}$ are known functions of the map coordinates and $K$ is an 'Austausch' coefficient equal to $3.5 \times 10^{6} \mathrm{~m}^{2} \mathrm{~s}^{-1}$; this value corresponds to the scale of migratory cyclones and anticyclones of the middle latitudes, which transport the heat in the atmosphere from the equator to the poles.

The surface temperature perturbation $\left(T_{\mathrm{s}}^{\prime}\right)$ on the oceans and continents can be expressed as a function of the mid-atmospheric temperature perturbation $\left(T_{\mathrm{m}}^{\prime}\right)$, the cloud cover $(\varepsilon)$ and the surface albedo $(\alpha)$ through the following linear algebraic equation:

$$
T_{\mathrm{s}}^{\prime}=F_{8}^{\prime} T_{\mathrm{sp}}^{\prime}+F_{8} T_{\mathrm{m}}^{\prime}+F_{9} \varepsilon+F_{10} \alpha+F_{11}
$$

where $T_{\mathrm{sp}}^{\prime}$ is the surface temperature perturbation in the previous month and $F_{8}^{\prime}, F_{8}, F_{9}, F_{10}$ and $F_{11}$ are known functions of the map coordinates, which are given by Adem (1965). $F_{8}^{\prime}$ is zero in the continents and different from zero in the oceans, so that $T_{\mathrm{s}}^{\prime}$ depends on $T_{\mathrm{sp}}^{\prime}$ in oceanic regions. The method to compute the cloud cover and the surface albedo of the cryosphere are given in Sections 3.1 and 3.2, respectively.

Eq. (1) is solved using the Liebmann relaxation method (Thompson, 1961), and the integration region is that of the US National Meteorological Center, a grid of 1977 points with $408.5 \mathrm{~km}$ resolution, which is superposed on the polar stereographic projection of the Northern Hemisphere. We assumed that the heat transport through the lateral boundary (close to $12^{\circ} \mathrm{N}$ ) is zero, so that the solution at the boundary is given by $T_{\mathrm{m}}^{\prime}=F_{2}^{\prime} / F_{1}^{\prime}$ which is also used as a first guess in the relaxation method to get the solution in the interior. The relaxation finishes when the numerical solutions in 2 consecutive iterations have a difference of $\sim 0.001^{\circ} \mathrm{C}$, which means that the model errors are $\sim 0.001^{\circ} \mathrm{C}$ for all the points in the integration region.

The solution of Eq. (1) is used in Eq. (2) to obtain the surface temperature of oceans and continents. In the TCM, a computed monthly change (DN) is obtained by subtracting the computed climatologic normal of reference (N) in the period 1961-1990, according to IPCC (2001, 2007), from its computed abnormal value. The annual values are obtained by averaging the corresponding 12 mo.

The TCM also computes the change in the latent heat released by condensation of water vapour in the clouds $\left(G_{5 \mathrm{DN}}\right)$ and the precipitation change is assumed to be proportional to $G_{5 \mathrm{DN}}$.

\section{FEEDBACK IN THE MODEL}

The TCM has 3 positive feedbacks associated with the 3 water phases, which are described by Adem \& Garduño (1998) and are considered in a detailed way in Chapter 7 of the IPCC Third Assessment Report (IPCC 2001).

\subsection{Snow/ice feedback}

In previous papers (Adem 1981a,b), the surface albedo is generated internally in the model by coupling the $0^{\circ} \mathrm{C}$ surface isotherm (over continental ground or ocean) with the boundary of the snow-ice layer. This coupling yields the temperature-snow/ice feedback, where an initial increase of temperature produces a decrement of the snow-ice layer on the ground or the ocean. This decrement of the snow-ice layer reduces the surface albedo, which produces an increase in the temperature, the opposite occurs for an 
initial decrement of temperature (positive feedback). In the present study, the extension of the snow-ice layer is computed by assuming that, for surface temperatures $<-4^{\circ} \mathrm{C}$, the surface is covered by snow and ice, and that it is free of snow and ice at temperatures $>4^{\circ} \mathrm{C}$. Between the isotherms of $\pm 4^{\circ} \mathrm{C}$, it is assumed that there is a linear transition of a surface with snowice to a surface without it. In this case, the surface albedo $(\alpha)$ can be expressed as a function of the surface temperature. Therefore, in agreement with Sellers (1969), we have the following expression for $\alpha$ :

$$
\alpha\left(t_{\mathrm{S}}\right)=\left\{\begin{array}{lc}
\alpha_{1} & \text { if } t_{\mathrm{S}}<-4^{\circ} \mathrm{C} \\
-\left(\frac{\alpha_{1}-\alpha_{0}}{8}\right) t_{\mathrm{S}}+\frac{\alpha_{1}+\alpha_{0}}{2} & \text { if }-4^{\circ} \mathrm{C} \leq t_{\mathrm{S}} \leq 4^{\circ} \mathrm{C} \\
\alpha_{0} & \text { if } t_{\mathrm{S}}>4^{\circ} \mathrm{C}
\end{array}\right.
$$

where $t_{\mathrm{S}}=T_{\mathrm{S}}-273.15^{\circ}, \alpha_{0}$ is the surface albedo with only permanent snow and/or ice on the ground, which in the present climate is taken as the normal value for August; and $\alpha_{1}$ is the surface albedo with snow and/or ice everywhere, which is taken as the normal value for January at grid points where there is snow or ice in that month and equal to $45 \%$ where there is neither snow nor ice in the same month.

\subsection{Cloud feedback}

The complexity of the response of clouds to climate changes was identified as a major source of uncertainty in the climate models (IPCC 2001, 2007). The clouds have the property of reflecting and absorbing the solar radiation and, therefore, to cool the Earth's surface. Additionally, they absorb and emit long-wave radiation and, consequently, warm the surface. In the TCM, the predominance of one of these effects over the other depends on the geographic position of clouds. In the polar regions, they warm the surface, mainly by absorption of terrestrial radiation (the greenhouse effect predominates). In mid and tropical latitudes, they cool the surface, mainly by reflection of solar radiation (the albedo effect predominates). Moreover, we suppose that the clouds absorb and emit longwave radiation as a black body, as is true for the Earth's surface. The changes in cloud cover, internally computed, are a linear function of the changes of the heat released by condensation of water vapour, which is a linear function of the computed changes in midtropospheric temperature (Adem 1965). An initial increase of temperature produces a decrement in the cloud cover, which favours an additional heating of the troposphere and the surface; the opposite occurs with an initial decrement of temperature (i.e. positive feedback). In the TCM, cloud cover is introduced as a normal mean value plus a change. Therefore, the frac- tional cloud cover $(\varepsilon)$ can be expressed (see Appendix 1) as:

$$
\varepsilon=\varepsilon_{\mathrm{Nob}}+\varepsilon_{\mathrm{DN}}+0.693 \varepsilon_{\mathrm{CRDN}}
$$

where $\varepsilon_{\mathrm{Nob}}$ is the seasonal normal value in the present climate, and $\varepsilon_{\mathrm{DN}}$ and $\varepsilon_{\mathrm{CRDN}}$ are the cloud cover changes computed by the model (internal forcing) and those generated by cosmic ray flux (external forcing), respectively. The factor 0.693 in Eq. (4) is the result of the superposition of the normal cover of high clouds $(13.5 \%)$ and middle clouds $(19.9 \%)$ The cloud cover changes, $\varepsilon_{\mathrm{DN}}$, are calculated as determined by Clapp et al. (1965) and incorporated to the TCM (Adem 1965). These changes are given by the following multiple regression equation:

$\varepsilon_{\mathrm{DN}}=d_{2}\left\{b^{\prime}\left(T_{\mathrm{m}}-T_{\mathrm{mN}}\right)+d^{\prime \prime} \frac{\partial}{\partial x}\left(T_{\mathrm{m}}-T_{\mathrm{mN}}\right)+c^{\prime \prime} \frac{\partial}{\partial y}\left(T_{\mathrm{m}}-T_{\mathrm{mN}}\right)\right\}$

where $d_{2}$ is a constant, $T_{\mathrm{mN}}$ is the normal value of $T_{\mathrm{m}}$, and $b^{\prime}, d^{\prime \prime}$ and $c^{\prime \prime}$ are the correlation coefficients, which depend on the space coordinates $x$ and $y$ and the season. The sum of the terms inside the brackets is equal to the latent heat changes released by the condensation of the water vapour.

\subsection{Water vapour feedback}

We hypothesise that the relative humidity in the troposphere remains constant over long-term changes in climate. When the temperature increases, as a result of the Clausius-Clapeyron equation, the atmospheric concentration of the water vapour should increase significantly in the atmosphere. Because water vapour is a powerful greenhouse gas, its incorporation in the climate models, with the assumption that the relative humidity remains constant, produces an important addition to the warming that results from the increase in the atmospheric $\mathrm{CO}_{2}$ concentration. This positive feedback of the water vapour is considered one of the most important feedbacks to take into account in climatic models, according to IPCC (2001).

In the TCM, the atmospheric layer absorbs and emits as black body between 0 and $8 \mu \mathrm{m}$, between 8 and $12 \mu \mathrm{m}$ it absorbs and emits a small fraction of the black body, and between 12 and $19 \mu \mathrm{m}$, in the shared band of the $\mathrm{H}_{2} \mathrm{O}$ and $\mathrm{CO}_{2}$, it absorbs and emits a fraction of the black body that depends on the content of precipitable water and $\mathrm{CO}_{2}$ in the atmosphere, in agreement with the logarithmic formulas of Smith (1969), described by Adem \& Garduño (1988). The change of precipitable water is computed by assuming that the relative humidity averaged in the troposphere is conserved with climate change. Thus, an initial increase in the temperature produces an increase in the precipitable 
water, which produces an increase in the absorption of longwave radiation and a tendency toward the saturation of the superposed bands of the $\mathrm{H}_{2} \mathrm{O}$ and $\mathrm{CO}_{2}$, giving an additional heating of the troposphere and surface. The opposite occurs with an initial decrement of temperature (positive feedback).

\section{EXTERNAL FORCING DATA}

The historical $\mathrm{CO}_{2}$ records of 1010-1975 come from 3 ice cores - DE08, DE08-2 and DSS in the Law Dome, East Antarctica - and are available from the Carbon Dioxide Information Analysis Center, Oak Ridge National Laboratory (http://cdiac.ornl.gov). The atmospheric $\mathrm{CO}_{2}$ concentration data, for the period 1010-1975, were taken from this web site. For the period 1976-1985, the atmospheric $\mathrm{CO}_{2}$ concentrations were obtained from NOAA (www.cmdl.noaa. gov/ccg/figures). Fig. 2 shows the annual atmospheric $\mathrm{CO}_{2}$ concentrations for the period 1010-1985 obtained from these 2 sources. The figure indicates that the $\mathrm{CO}_{2}$ concentration remains approximately constant at 280 ppm from 1010 to 1550. Between 1550 and 1800, a relative minimum, marked by a reduction of $\sim 10 \mathrm{ppm}$, is observed, probably caused by the decrement in temperature during the Little Ice Age. From 1850 onwards, a persistent increase in the $\mathrm{CO}_{2}$ concentration is observed, caused mainly by the burning of fossil fuels.

Solar irradiance is the solar activity product that has the most obvious impact on the Earth's climate. The reconstruction of the TSI for 1610-2000 is presented in Fig. 3 and was taken from Lean (2000). We observe that the Maunder Minimum ( 1645-1710) is the longest time span that presented a nearly constant TSI $\left(\sim 1363.5 \mathrm{~W} \mathrm{~m}^{-2}\right)$.

Svensmark (1998) assumed that the high-energy secondary particles produced by the cosmic ray fluxes

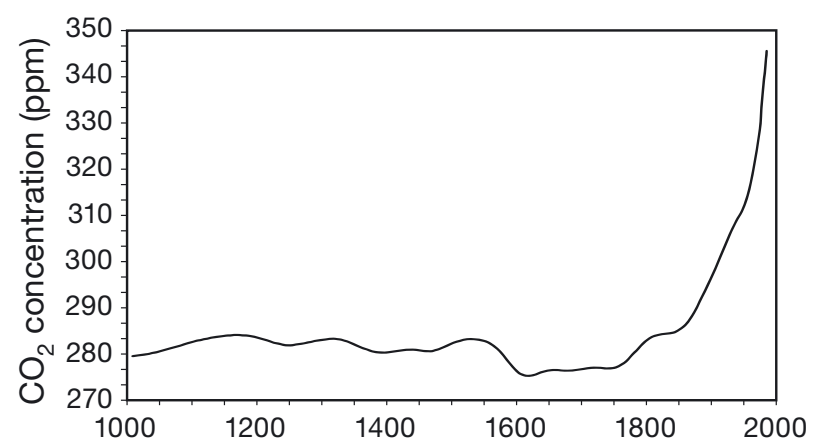

Fig. 2. Annual atmospheric $\mathrm{CO}_{2}$ concentration for the period 1010-1985. Between 1010 and 1975, data were taken from the Carbon Dioxide Information Analysis Center, Oak Ridge National Laboratory (http://cdiac.ornl.gov). For the period 1976-1985, data were obtained from NOAA (www.cmdl. noaa.gov/ccg/figures)

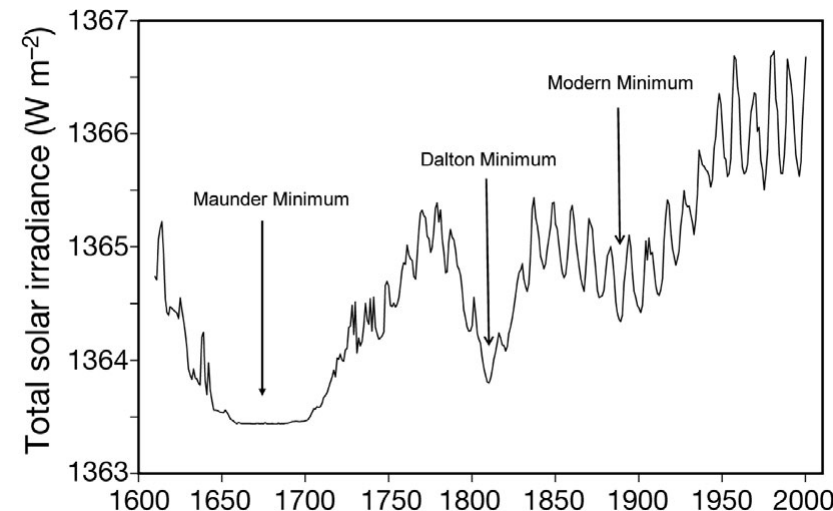

Fig. 3. Total solar irradiance (TSI) annual mean from 1610 to 2000 (Lean 2000). Between 1900 and 2000, an increase of $\sim 0.09 \%$ in the TSI was observed. From 1675 (Maunder Minimum) to 2000, the increase was almost $0.2 \%$

can penetrate the atmosphere to depths of low cloud formation. Later, Marsh \& Svensmark (2000) reconstructed the change in LCC using the changes in cosmic ray fluxes measured in the neutron monitor at Huancayo, Peru. The available period of LCC data was from 1983 to 1994; they extended their LCC reconstruction to 1952-1999. According to Marsh \& Svensmark (2000), the global mean for LCC for the period $1983-1994$ is $28 \%$. Using this value, we obtained a linear correlation between the reconstructed LCC percentage $(28 \%$ plus its changes induced by cosmic ray changes) and the ${ }^{10} \mathrm{Be}$ concentration (Beer 2000), considering a 1 yr delay between the 2 series (Fig. 4). The correlation coefficient for the period $1952-1985$ is 0.60 .

Fig. 5 shows the LCC percentage $(28 \%$ plus its changes), obtained from the linear regression equation in Fig. 4 and the ${ }^{10} \mathrm{Be}$ time series for the period 1425-1985.

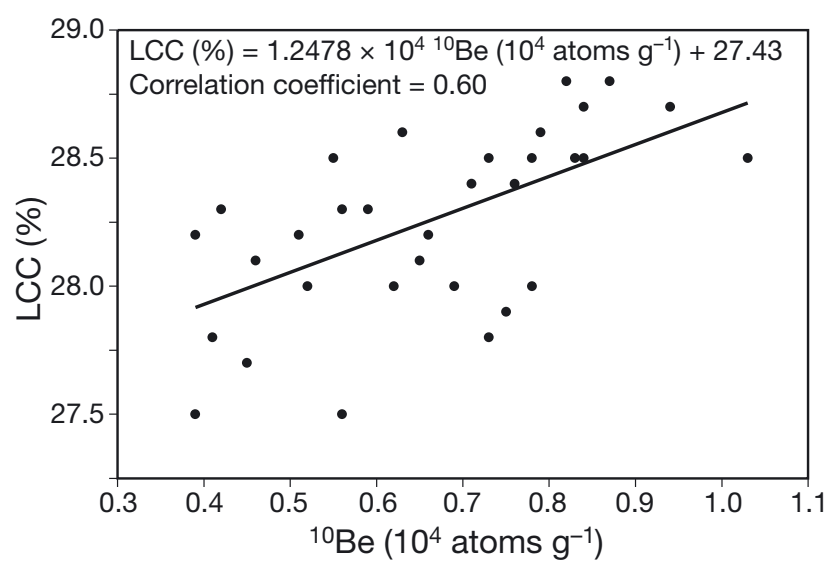

Fig. 4. Linear regression between the annual reconstructed low cloud cover (LCC, \%), obtained from cosmic ray flux (Marsh \& Svensmark 2000), and ${ }^{10} \mathrm{Be}$ concentration $\left(10^{4}\right.$ atoms $\left.{ }^{-1}\right)$ data (Beer 2000) for the period 1952-1985 


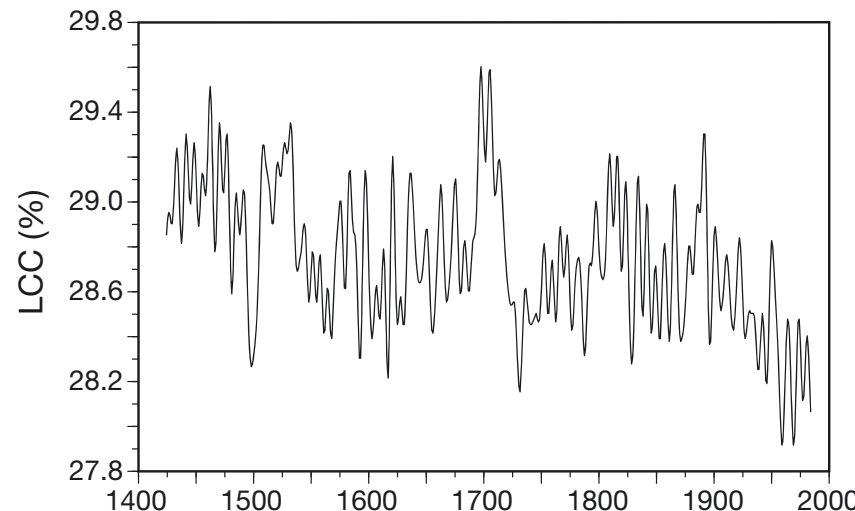

Fig. 5. Annual time series of low cloud cover (LCC, \%) induced by cosmic ray fluxes obtained from the linear regression equation shown in Fig. 4 and using the ${ }^{10} \mathrm{Be}$ time series for the period 1425-1985

\section{NUMERICAL EXPERIMENTS}

In the TCM, the 3 mechanisms of positive feedback are taken into account and 2 types of experiments are carried out. (1) TCM1 includes the annual changes in TSI and atmospheric $\mathrm{CO}_{2}$ concentration; (2) TCM2 also includes changes in the TSI and $\mathrm{CO}_{2}$, as well as the annual changes in LCC induced by cosmic rays. In both experiments, the model is run for the period 1610-
1985, which is inside the second half of the Little Ice Age and contains the Maunder ( 1645-1710), Dalton ( 1795-1823) and Modern minima.

An index of agreement (IOA) between the computed annual surface temperature anomalies, averaged over the Northern Hemisphere, and the corresponding reconstructions carried out by different authors was used. The IOA reflects the degree of exactness with which a model computes the size and distribution of a variable, regardless of units. This index varies between 0 and 1 ; a value of 1 indicates perfect agreement between the observed and computed values and 0 denotes a complete disagreement. Willmott (1981) expresses the IOA as:

$$
\text { IOA }=1-\frac{\sum_{i=1}^{M}\left(C_{i}-O_{i}\right)^{2}}{\sum_{i=1}^{M}\left[\left|C_{i}-\bar{O}\right|+\left|O_{i}-\bar{O}\right|\right]^{2}}
$$

where $C_{i}$ is the $i$-value of the computed variable, $O_{i}$ is the $i$-value of the observed variable, $O$ is the mean value of the observed variable and $M$ is the number of values that each variable takes.

\section{RESULTS AND DISCUSSION}

In Fig. 6 we present the 5 yr running mean of the Northern Hemisphere mean temperature anomalies

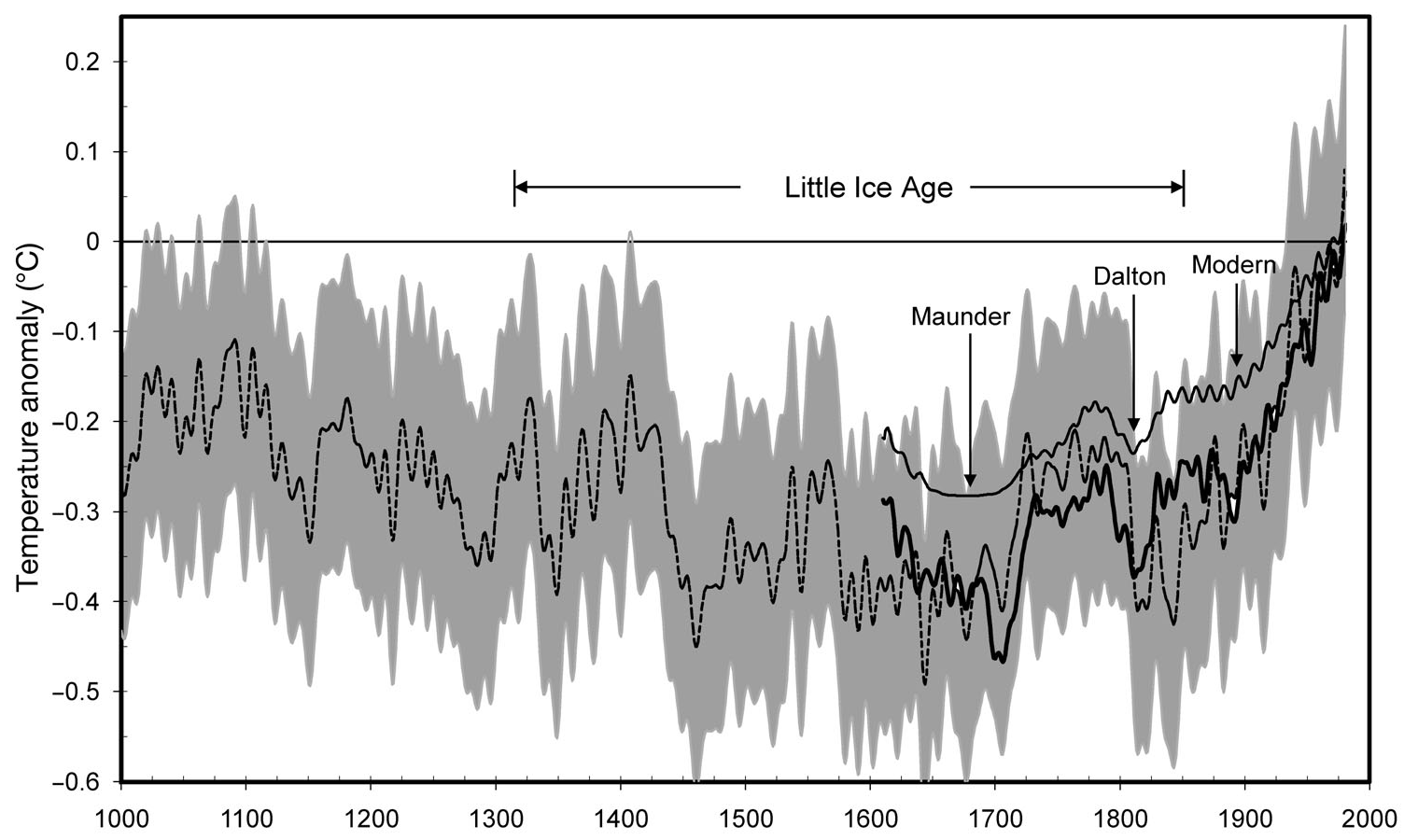

Fig. 6. The 5 yr running mean of the Northern Hemishpere mean surface temperature anomalies relative to the 1961-1990 period. Dashed line: reconstruction of Mann \& Jones (2003). Thin solid line: TCM1 computed anomalies including only the total solar irradiance (TSI) and atmospheric $\mathrm{CO}_{2}$ concentration data. Thick solid line: TCM2 results using TSI, $\mathrm{CO}_{2}$ concentration and LCC induced by cosmic rays. Grey shading: $\pm 2 \mathrm{SE}$ 
for the period 1610-1985 for both experiments. For comparison purposes, the reconstruction of Mann \& Jones (2003) in the period 1000-1985 is also shown. The IOA between the temperature reconstruction of Mann \& Jones (2003) and TCM1 and TCM2 are shown in Table 1. It is clear that TCM2 represents the reconstructed time series better than TCM1 (Fig. 6, Table 1). Moreover, Table 2 shows the largest drops in tempera-

Table 1. Northern Hemisphere temperature anomaly means and the index of agreement (IOA) between a temperature reconstruction and the TCM1 and TCM2 experiments for the period 1610-1985

\begin{tabular}{|lcc|}
\hline vTime series & Mean $\left({ }^{\circ} \mathrm{C}\right)$ & IOA \\
\hline Mann \& Jones (2003) & -0.28 & - \\
TCM1 & -0.19 & 0.75 \\
TCM2 & -0.28 & 0.92 \\
\hline
\end{tabular}

Table 2. Comparison of the 3 minima temperature anomalies between the TCM1 and TCM2 experiments. Percentage $(\%)=$ [(TCM2 - TCM1)/TCM1] $\times 100$

\begin{tabular}{|lccc|}
\hline Minima & $\begin{array}{r}\text { Temperature anomalies }\left({ }^{\circ} \mathrm{C}\right) \\
\text { TCM1 }\end{array}$ & $\begin{array}{c}\text { Percentage } \\
\text { TCM } 2\end{array}$ \\
\hline Maunder & -0.27 & -0.46 & 70 \\
Dalton & -0.22 & -0.37 & 68 \\
Modern & -0.17 & -0.31 & 82 \\
\hline
\end{tabular}

ture during the 3 minima considered. In comparison to TCM1, the inclusion of clouds (TCM2) induces a stronger decline in temperature (68 versus $82 \%$ ).

In Fig. 7 we present the 5 yr running means of the mean surface temperature anomalies of 6 time series reconstructed by several authors for April-September (all starting in 1000 and ending in different years) in continental regions north of $20^{\circ} \mathrm{N}$; the figure also shows the TCM2 results (along 1610-1985) and the observed data for the period 1873-1985. The TCM2 temperature anomaly means, the mean of the observed time series and the IOA between those series are presented in Table 3. In general, the TCM2 experiment shows good agreement with the various reconstructed

Table 3. Northern Hemisphere April-September means of surface temperature anomalies and the index of agreement (IOA) between several temperature reconstructions and the TCM2 results

\begin{tabular}{|lccc|}
\hline Time series & Period & Mean $\left({ }^{\circ} \mathrm{C}\right)$ & IOA \\
\hline Jones et al. (1998) & $1610-1985$ & -0.29 & 0.74 \\
Mann et al. (1999) & $1610-1979$ & -0.22 & 0.60 \\
Briffa et al. (2001) & $1610-1958$ & -0.34 & 0.69 \\
Briffa (2000) & $1610-1985$ & -0.29 & 0.76 \\
Overpeck et al. (1997) & $1610-1985$ & -0.27 & 0.72 \\
Crowley \& Lowery (2000) & $1610-1985$ & -0.37 & 0.83 \\
Jones et al. (1999) & $1873-1985$ & -0.13 & 0.74 \\
TCM2 & $1610-1985$ & -0.37 & - \\
\hline
\end{tabular}

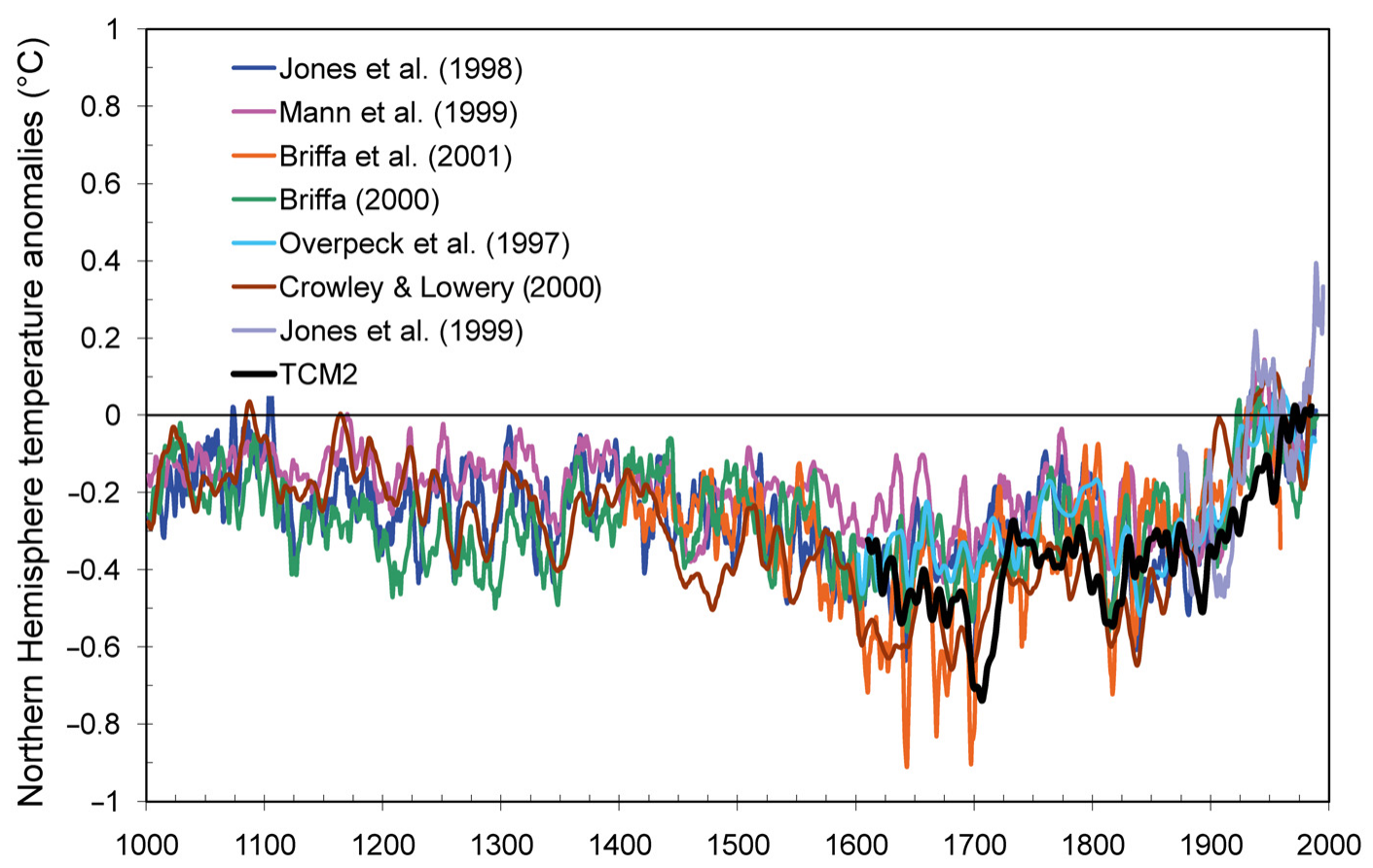

Fig. 7. The 5 yr running mean of the surface temperature anomalies, relative to the 1961-1990 period. The 8 time series correspond to the April-September mean anomalies from all land regions north of $20^{\circ} \mathrm{N}$. The TCM2 temperature anomalies are computed using total solar irradiance, atmospheric $\mathrm{CO}_{2}$ concentration and low cloud cover (LCC) induced by cosmic rays 
and observed temperature anomalies, the highest agreement being with the reconstruction of Crowley \& Lowery (2000) (Fig. 7, Table 3). For a review of several reconstructed temperatures for the past 2 millennia, see also Jones \& Mann (2004).

Fig. 8 shows the TCM2 Northern Hemishpere surface anomalies in temperature $\left({ }^{\circ} \mathrm{C}\right)$ and precipitation $(\%)$ for summer and winter for 1707 . This year is at the end of the Maunder Minimum (Fig. 3), when the percentage of LCC reached the highest value of the period 1425-1985 (Fig. 5) and the effect of the cosmic
ray-LCC relationship on surface temperature was stronger. Fig. 8a,b shows a generalized cooling in the Northern Hemisphere during summer and winter, which is greater on the continents and in high latitudes. The cooling in summer is associated with a decrement in precipitation in the North Central Atlantic and the Caribbean Sea, and an increase in precipitation around $30^{\circ} \mathrm{N}$ on continental areas, mainly in North Africa and SE Asia (Fig. 8c). In winter, the cooling is associated with a decrement of precipitation in high latitudes (Fig. 8d).
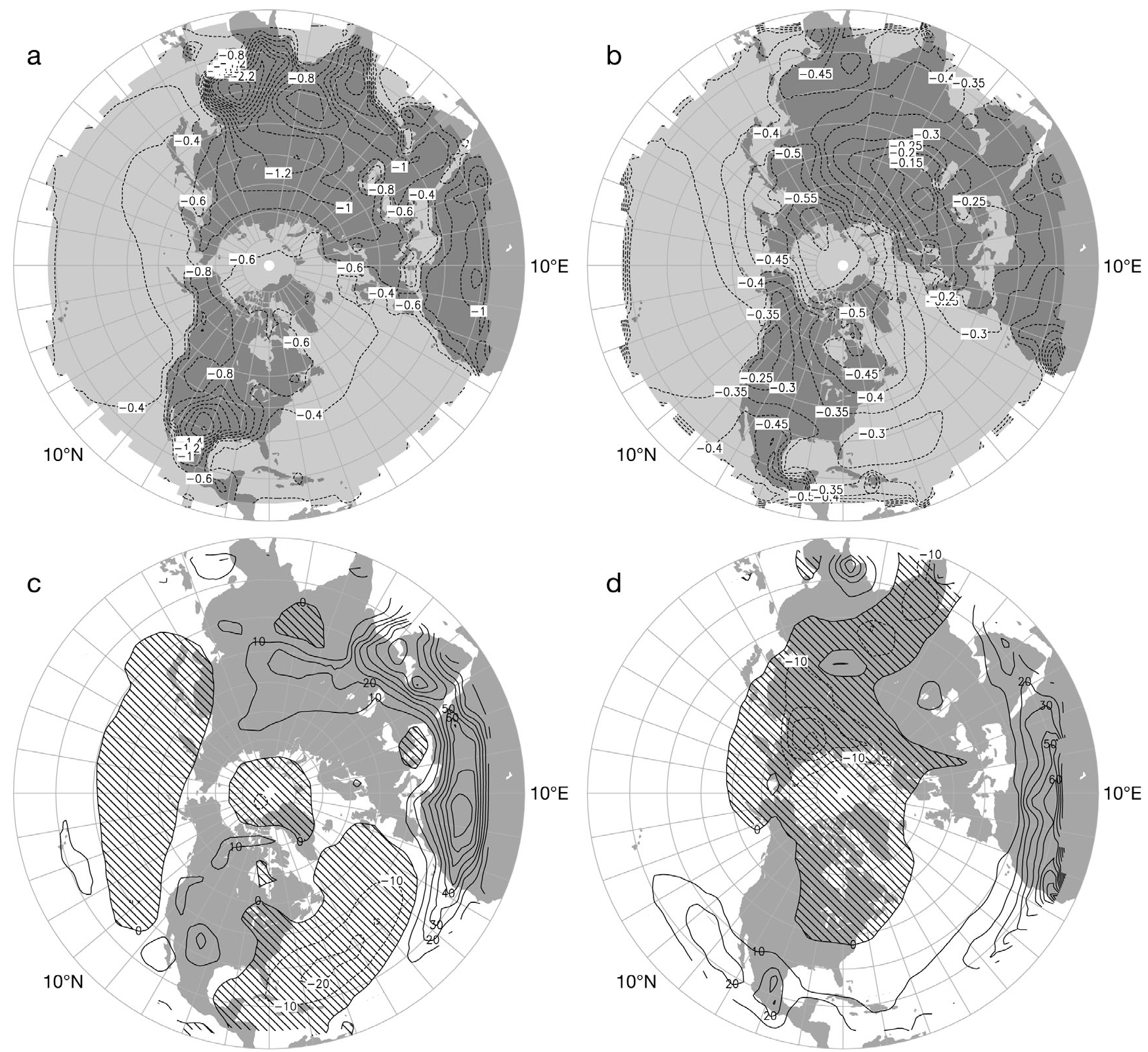

Fig. 8. Northern Hemisphere $(\mathrm{a}, \mathrm{b})$ surface temperature anomalies $\left({ }^{\circ} \mathrm{C}\right)$ and $(\mathrm{c}, \mathrm{d})$ precipitation anomalies $(\%$; hatched areas: negative values) in $(\mathrm{a}, \mathrm{c})$ summer and $(\mathrm{b}, \mathrm{d})$ winter relative to 1961-1990 obtained from the TCM2 experiment. The anomalies are computed for 1707 
The long-term Palmer Drought Severity Index (PDSI) reconstruction is reported by Esper et al. (2007) for the past 953 yr in Morocco, NW Africa. The PDSI reconstruction shows generally drier conditions before $\sim 1350$, a transition period from dry to wet conditions between $\sim 1350$ and $\sim 1450$, and generally wetter conditions during most of the Little Ice Age until the 1970s. This reconstruction is in concordance with the computed precipitation by the TCM for summer and winter in NW Africa (Fig. 8c,d).

Of particular interest is the computed rainfall for summer in Mexico (Fig. 8a), which is consistent with that reported by Lozano-García et al. (2007). These authors point out that the dry summer conditions in the Caribbean Sea and in the NW Yucatan during the Little Ice Age are related to a southward displacement of the Intertropical Convergence Zone and, consequently, to a reduction in the moisture supply by trade winds from the Caribbean Sea.

The registered volcanic activity during the studied period provides a forcing of approximately $-6.0 \mathrm{~W} \mathrm{~m}^{-2}$ for the most intense volcanic event (Crowley 2000), but in a relatively short time $(\sim 2 \mathrm{yr})$ compared with the climatic response. Nevertheless, also it can be a possible cause of additional cooling that has not been taken into account in the present experiments. In a future study it will be included in the model.

\section{CONCLUSIONS}

We found that a reduction in solar activity can produce a cooling of the planetary surface temperature, caused by both a decrease in the TSI and an increase in the LCC. The latter is assumed to be produced by an atmospheric ionization increase owing to the increases in cosmic rays. The strongest decreases in temperature during the 3 solar activity minima considered in the present study were approximately $-0.46^{\circ} \mathrm{C}$ for Maunder, $-0.37^{\circ} \mathrm{C}$ for Dalton and $-0.31^{\circ} \mathrm{C}$ for Modern.

The experiments carried out show that the changes in the reconstructed LCC obtained from ${ }^{10} \mathrm{Be}$ can significantly reduce the simulated surface temperature, as is shown by the comparison between the TCM1 and TCM2 experiments. Moreover, there is good agreement between TCM2 and the reconstructed temperature anomalies. The agreement between the reconstructed and the TCM temperature anomalies is better for TCM2 than for TCM1.

Also, the experiments show a generalized cooling in the Northern Hemisphere, which turns out to be greater on the continents and at high latitudes. This cooling is associated with a decrement in precipitation at high latitudes in the winter and in oceanic areas in the summer, and an increase at low latitudes, mainly in North Africa.
Acknowledgements. This work was partially supported by DGAPA-UNAM-IN103209-3 and CONACYT-F282795 grants. We also thank the academic technicians B. Oda, A. Aguilar and R. Meza for their support in the accomplishment of this work.

\section{LITERATURE CITED}

Adem J (1964) On the physical basis for the numerical prediction of monthly and seasonal temperature in the troposphere-ocean-continent system. Mon Weather Rev 92: 91-104

Adem J (1965) Experiments aiming at monthly and seasonal numerical weater prediction. Mon Weather Rev 93:495-503

> Adem J (1970) Incorporation of advection of heat by mean winds and by ocean currents in a thermodynamic model for long-range weather prediction. Mon Weather Rev 98: $776-786$

Adem J (1979) Low resolution thermodynamic grid models. Dynam Atmos Ocean 3:433-451

Adem J (1981a) Numerical simulation of the annual cycle of climate during the ice ages. J Geophys Res 86: 12015-12034

Adem J (1981b) Numerical experiments on the ice age climates. Clim Change 3:155-171

Adem J (1991) Review development and applications of the Adem thermodynamic climate model. Clim Dyn 5: $145-160$

Adem J, Garduño R (1988) Interactive long wave spectrum for the thermodynamic model. Atmósfera 1:157-172

Adem J, Garduño R (1998) Feedback effects of atmospheric $\mathrm{CO}_{2}$-induced warming. Geofis Int 37:55-70

Adem J, Mendoza VM, Ruiz A, Villanueva EE, Garduño R (2000) Recent numerical experiments on three-months extended and seasonal weather prediction with a thermodynamic model. Atmósfera 13:53-83

Beer J (2000) Long-term indirect indices of solar variability. Space Sci Rev 94:53-66

Beer J, Vonmoos M, Muscheler R (2006) Solar variability over the past several millennia. Space Sci Rev 125:67-79

Briffa KR (2000) Annual climate variability in the Holocene: interpreting the message of ancient trees. Quat Sci Rev 19: 87-105

Briffa KR, Osborn TJ, Schweingruber FH, Harris IC, Jones PD, Shiyatov SG, Vaganov EA (2001) Low-frequency temperature variations from a northern tree-ring-density network. J Geophys Res 106:2929-2941

Caprioli D, Amato E, Blasi P (2010) The contribution of supernova remnants to the galactic cosmic ray spectrum. Astropart Phys 33:160-168

Clapp PF, Scolnik SH, Taubensee RE, Winninghoff FJ (1965) Parameterization of certain atmospheric heat sources and sinks for use in a numerical model for monthly and seasonal forecasting. Extended Forecast Division, US Weather Bureau, Washington, DC

> Crowley TJ (2000) Causes of climate change over the past 1000 years. Science 289:270-277

Crowley TJ, Lowery TS (2000) Northern Hemisphere temperature reconstruction. Ambio 29:51-54

Cubasch U, Voss R, Hegerl GC, Vo BR (1997) Simulation of the influence of solar radiation variations on the global climate with an ocean-atmosphere general circulation model. Clim Dyn 13:757-767

Dorman LI (2004) Cosmic Rays in the Earth's atmosphere and underground. Astrophysics and Space Science Library, Vol 303. Kluwer, Dordrecht 
Erlykin AD, Gyalai G, Kudela K, Sloan T, Wolfendale AW (2009) On the correlation between cosmic ray intensity and cloud cover. J Atmos Solar-Terr Phys 71:1794-1806

Esper J, Frank DC, Büntgen U, Verstege A, Luterbacher J, Xoplaki E (2007) Long-term drought severity variations in Morocco. Geophys Res Lett 34:L17702 doi:10.1029/2007 GL030844

Heber B, Fichtner H, Scherer K (2006) Solar and heliospheric modulation of galactic cosmic rays. Space Sci Rev 125: 81-93

IPCC (2001) Climate Change 2001: the scientific basis. Contribution of Working Group I to the Third Assessment Report of the Intergovernmental Panel on Climate Change. Cambridge University Press, Cambridge

IPCC (2007) Climate Change 2007: the physical science basis. Contribution of Working Group I to the Fourth Assessment Report of the Intergovernmental Panel on Climate Change. Cambridge University Press, Cambridge

Jones PD, Mann ME (2004) Climate over past millennia. Rev Geophys 42:1-42

Jones PD, Briffa KR, Barnett TP, Tett SFB (1998) High-resolution paleoclimatic records for the last millennium: interpretation, integration and comparison with general circulation model control-run temperatures. Holocene 8: 455-471

Jones PD, New M, Parker DE, Martin S, Rigor IG (1999) Surface air temperature and its changes over the past 150 years. Rev Geophys 37:173-199

Kristjánsson JE, Stjern CW, Stordal F, Fjaeraa AM, Jónasson K (2008) Cosmic rays, cloud condensation nuclei and clouds: a reassessment using MODID data. Atmos Chem Phys 8:7373-7387

Lean J (2000) Evolution of the Sun's spectral irradiance since the Maunder Minimum. Geophys Res Lett 27:2425-2428

Lozano-Garcia S, Caballero M, Ortega B, Rodriguez A, Sosa S (2007). Tracing the effects of the Little Ice Age in the tropical lowlands of eastern Mesoamerica. Proc Natl Acad Sci USA 104:16200-16203

> Mann ME, Jones PD (2003) Global surface temperatures over the past two millennia. Geophys Res Lett 30:1820-1823

> Mann ME, Bradley RS, Hughes MK (1999) Northern Hemisphere temperatures during the past millennium: Inferences, uncertainties, and limitations. Geophys Res Lett 26: $759-762$

Marsh ND, Svensmark H (2000) Low cloud properties influenced by cosmic rays. Phys Rev Lett 85:5004-5007

McCracken KG, McDonald FB (2001). The long term modulation of the galactic cosmic radiation, 1500-2000. In: Kampert KH, Hainzelmann G, Spiering C, Simon M and others (eds) Proc 27th Int Cosmic Ray Conf, 17-5 August 2001. Dat-Hex, Katlenburg-Lindau, p 3753-3756

Overpeck JT, Hughen $\mathrm{K}$, Hardy D, Bradley R, and others
(1997) Arctic environmental change of the last four centuries. Science 278: 1251-1256

Pallé-Bagó E, Butler CJ (2000) The influence of cosmic rays on terrestrial clouds and global warming. Astron Geophys 41: 418-422

Ramirez J, Mendoza B, Mendoza VM, Adem J (2004) Modelling the effect of an assumed cosmic ray-modulated global cloud cover on the terrestrial surface temperature. J Atmos Solar-Terr Phys 66:1683-1690

Sellers WD (1969) A global climatic model based on the energy balance of the earth-atmosphere system. J Appl Meteorol 8:392-400

Smith WL (1969) A polynomial representation of carbon dioxide and water vapor transmission. ESSA (Environmental Science Services Administration) Tech Rep NESC 47, US Department of Commerce, Washington, DC

Solanki SK, Krivova NA (2006) Solar variability of possible relevance for planetary climates. Space Sci Rev 125:25-37

Svensmark H (1998) Influence of cosmic rays on climate. Phys Rev Lett 81:5027-5030

Svensmark H (2007) Cosmoclimatology: a new theory emerges. Astron Geophys 48:1.18-1.24

Svensmark H, Friis-Christensen E (1997) Variation of cosmic ray flux and global cloud coverage: a missing link in solar-climate relationships. J Atmos Solar-Terr Phys 59: $1225-1232$

Thompson PD (1961) Numerical weather analysis and prediction. The MacMillan Company, New York, NY

Usoskin IG, Marsh N, Kovaltsov GA, Mursula K, Gladysheva OG (2004) Latitudinal dependence of low cloud amount on cosmic ray induced ionization. Geophys Res Lett 31: L16109 doi:10.1029/2004GL019507

Voiculescu M, Usoskin IG, Mursula K (2006) Different response of clouds to solar input. Geophys Res Lett 33:L21802 doi:10. 1029/2006GL027820

- Webber WR, Cummings AC, McDonald FB, Stone EC, Heikkila B, Lal N (2009) Transient intensity changes of cosmic rays beyond the heliospheric termination shock as observed at Voyager 1. J. Geophys Res A 114:A07108 doi: 10.1029/2009JA014156

Willmott CJ (1981) On the validation of models. Phys Geogr 2: 184-194

WMO (World Meteorological Organization) (1966) International meteorological vocabulary. No. 182 TP. 91, Secretariat of the WMO, Geneva

- Yu F, Turco RP (2000) Ultrafine aerosol formation via ionmediated nucleation. Geophys Res Lett 27:883-886

> Zorita E, Von Storch H, Gonzalez-Rouco FJ, Cubasch U Legutke S, Schlese U (2004) Climate evolution in the last five centuries simulated by an atmosphere-ocean model: global temperatures, the North Atlantic Oscillation and the Late Maunder Minimum. Meteorol Z 13:271-289 
Appendix 1. Cloud parameterization

If we suppose that the change in the cosmic ray flux arriving to the atmosphere can induce a change in LCC, then the total fractional cloud cover, $\varepsilon_{\mathrm{T}}$, can be expressed as:

$$
\varepsilon_{\mathrm{T}}=1-\left(1-\varepsilon_{\mathrm{H}}\right)\left(1-\varepsilon_{\mathrm{M}}\right)\left(1-\varepsilon_{\mathrm{L}}-\varepsilon_{\mathrm{CRDN}}\right)
$$

where $\varepsilon_{\mathrm{H}}, \varepsilon_{\mathrm{M}}$ and $\varepsilon_{\mathrm{L}}$ are the high, mid and low cloud covers, respectively, and $\varepsilon_{\mathrm{CRDN}}$ is the LCC change induced by cosmic rays.

Eq. (A1) can be expressed as:

$$
\varepsilon_{\mathrm{T}}=\varepsilon+\left(1-\varepsilon_{\mathrm{H}}\right)\left(1-\varepsilon_{\mathrm{M}}\right) \varepsilon_{\mathrm{CRDN}}
$$

where:

$$
\varepsilon=1-\left(1-\varepsilon_{\mathrm{H}}\right)\left(1-\varepsilon_{\mathrm{M}}\right)\left(1-\varepsilon_{\mathrm{L}}\right)
$$

is the cloud cover generated by internal processes in the atmosphere.

Moreover, we can express this cloud cover as:

$$
\varepsilon=\varepsilon_{\mathrm{N}}+\varepsilon_{\mathrm{DN}}
$$

where $\varepsilon_{N}$ is the normal value (long-term mean) of $\varepsilon$ and $\varepsilon_{\mathrm{DN}}$ is the change or anomaly of $\varepsilon$ internally generated. $\varepsilon_{\mathrm{N}}$ can be expressed by Eq. (A3) by using normal values for the high, mean and low cloud covers. Moreover, $\varepsilon_{\mathrm{DN}}$ can be expressed approximately by the following equation:

$\varepsilon_{\mathrm{DN}}=\left(1-\varepsilon_{\mathrm{MN}}\right)\left(1-\varepsilon_{\mathrm{LN}}\right) \varepsilon_{\mathrm{HDN}}+\left(1-\varepsilon_{\mathrm{HN}}\right)\left(1-\varepsilon_{\mathrm{LN}}\right) \varepsilon_{\mathrm{MDN}}+\left(1-\varepsilon_{\mathrm{HN}}\right)\left(1-\varepsilon_{\mathrm{MN}}\right) \varepsilon_{\mathrm{LDN}}$

where the $\mathrm{N}$ and $\mathrm{DN}$ subscripts refer to normal and changes or anomalies (departure from normal), respectively. In Eq. (A5) we have eliminated nonlinear terms containing the products of the form: $\varepsilon_{\mathrm{HDN}} \varepsilon_{\mathrm{MDN}}, \varepsilon_{\mathrm{HDN}} \varepsilon_{\mathrm{LDN}}$ and $\varepsilon_{\mathrm{MDN}} \varepsilon_{\mathrm{LDN}}$.

In agreement with Marsh \& Svensmark (2000), $\varepsilon_{\mathrm{H}}=13.5 \%$ and $\varepsilon_{\mathrm{M}}=19.9 \%$ are the normal values $\mathbf{1}$ for high and medium cloud cover for the period from July 1983 to September 1994. Therefore, using these values and Eq. (A4) in Eq. (A2), we obtain an equation that can be used in the thermodynamic climate model (TCM):

$$
\varepsilon=\varepsilon_{\mathrm{Nob}}+\varepsilon_{\mathrm{DN}}+0.693 \varepsilon_{\mathrm{CRDN}}
$$

where we have changed $\varepsilon_{\mathrm{T}}$ to $\varepsilon_{\text {, and now }} \varepsilon_{\text {Nob }}$ represents the observed normal cloud cover.

In the TCM, $\varepsilon_{\mathrm{DN}}$ is computed as follows:

$$
\varepsilon_{\mathrm{DN}}=D_{2} G_{5 \mathrm{DN}}
$$

where $D_{2}$ is an empirical constant and $G_{5 \mathrm{DN}}$ is the change or anomaly of the latent heat released by condensation of water vapour computed by the model (Clapp et al. 1965, Adem 1965).

${ }^{1}$ Climatological or normal values are computed using a long period of $30 \mathrm{yr}$. In the case of missing data, the normal values can be computed using periods of at least 10 yr (WMO 1966)

Editorial responsibility: Mikhail Semenov,

Harpenden, UK
Submitted: January 18, 2010; Accepted: September 19, 2010 Proofs received from author(s): November 23, 2010 